\title{
UNAPREĐENJE SISTEMA MENADŽMENTA ŽIVOTNOM SREDINOM U PREDUZEĆU MAGYAR SZO
}

\section{IMPROVEMENT OF THE ENVIRONMENTAL MANAGEMENT SYSTEM AT THE COMPANY MAGYAR SZO}

\author{
Ivona Varga, Fakultet tehničkih nauka, Novi Sad
}

\section{Oblast - INDUSTRIJSKO INŽENJERSTVO I MENADŽMENT}

Kratak sadržaj - Tema rada jeste sistem menadžmenta životnom sredinom i njegovo unapređenje. „Ovim međunarodnim standardom se specificiraju zahtevi za sistem menadžmenta životnom sredinom koje organizacija može da koristi da unapredi svoje performanse životne sredine” [1]. Cilj rada jeste da se na primeru rada preduzeća Magyar Szo analizira proces skladištenja, nabavke $i$ novinske rotacije, kakav on ima uticaj na životnu sredinu, te da se analiziraju problemi samih procesa $i$ da predlog rě̌enja za unapređenje.

Ključne reči: Sistem, Menadžment, Životna sredina, Unapređenje, Standard

Abstract - The theme of the paper is the environmental management system and its improvement. "This international standard specifies the requirements for an environmental management system that organizations can use to improve their environmental performance" [1]. The aim of the paper is to analyze, in the case of Magyar Szo's work, the process of storing, purchasing and newspaper rotation, what kind of environmental impact it has, and analyzing the problems of the processes themselves and proposing solutions for improvement.

Keywords: System, Management, Environment, Improvement, Standard

\section{UVOD}

„Zabrinutost javnosti kada je reč o posledicama ekonomskih aktivnosti na životnu sredinu značajno se povećala poslednjih godina širom sveta. Velike ekološke katastrofe su podstakle globalnu raspravu o odgovornosti kompanija $\mathrm{i}$ istakle potrebu njihovog uključivanja $\mathrm{u}$ proces rešavanja ključnih pitanja $u$ vezi sa zaštitom životne sredine. Svaka privreda, kao i svaka druga ljudska delatnost, ima određeni uticaj na životnu sredinu, te je stoga inicijativa o afirmisanju društvene odgovornosti $u$ prirodnom okruženju od podjednakog značaja za sve kompanije, bez obzira na veličinu i vrstu delatnosti“" [2]. Delatnost preduzeća koje je tema ovog rada jeste izdavanje, štampanje i distribucija dnevnih novina. Stamparije u toku procesa proizvodnje stvaraju otpad.

\section{NAPOMENA:}

Ovaj rad proistekao je iz master rada čiji mentor je bio dr Dragoljub Šević.
Taj otpad nastaje kao posledica različitih procesa proizvodnje: izrada štamparske ploče, obrada slike, štampanje i završna grafička obrada. Da bi došlo do redukcije otpada, preduzeća moraju posebno skrenuti pažnju na upravljanje otpadom. To zahteva promenu stava i generalno prakse preduzeća gde se veća pažnja posvećuje sprečavanju i redukovanju otpada, nego njegovom tretiranju i uklanjanju.

\section{TEORIJSKE OSNOVE \\ 2.1. Skladištenje}

„Skladište je logistički prostor u kome roba ima stacionarno stanje, jer ne učestvuje direktno u procesu proizvodnje ili pružanja usluga. Stacionarno stanje označava robu na raspolaganju, koja se tek kasnije uključuje $\mathrm{u}$ proces proizvodnje novih vrsta roba ili $\mathrm{u}$ pružanje usluga korisnicima koji imaju potrebu za robom“ [3].

Najvažniji pojmovi koji se odnose na skladište su:

- strategija skladišta,

- funkcije skladišta,

- tokovi materijala,

- kretanje robe ka, iz i u skladištu praćeno sa informacionim i vrednosnim tokovima,

- troškovi skladištenja i

- upravljanje skladištem.

\subsection{Nabavka}

"Nabavka se može smatrati jednim procesom čiji je zadatak da obezbedi sirovine, materijale, standardnu robu, pomoćne materijale, gotove proizvode i agregate koji se tehnološki tretiraju ili ugrađuju $u$ procesu proizvodnje a za potrebe tržišta. Nabavka takođe podrazumeva obezbeđenje usluga za potrebe organizacije" [4].

Za uspešno obavljanje svog zadatka nabavka mora imati jasno definisane zahteve kroz:

- tehničku dokumentaciju,

- specifikacije,

- plan proizvodnje i

- zahtev za nabavku.

\subsection{Novinska rotacija}

Prvu novinsku (ofset) rotaciju za štampanje novina izgradio je i patentirao Casper Hermann 1907. godine. To je ofsetna rotacija sa štamparskim agregatom u kome su se nalazila četiri cilindra, koja su omogućavala obostranu štampu na traku po "guma-guma" principu. 
Savremene ofsetne rotacije grade se sa više štamparskih agregata koji se spajaju u vodoravnu liniju i okomito na spratove tj. grade se u više etaža. Ofsetne rotacije za štampu novina i časopisa (manjeg ili većeg opsega odnosno jednobojne i višebojne), kao i rotacije za štampu knjižnih araka, etiketa, beskonačnih obrazaca itd., grade se slaganjem i spajanjem više identičnih štamparskih agregata i drugih aparata. $U$ ofsetne štamparske agregate pored cilindara ugrađuju se uređaji za bojenje i vlaženje koji osiguravaju sigurno vlaženje i bojenje ofsetnih štampanih formi pri vrlo velikim brzinama štampe.

\section{O PREDUZEĆU}

Preduzeće DOO Mayar SZO KFT je privredno društvo OSNOVANO 27.02.2002. sa osnovnom ulogom informisanja stanovništva mađarske nacionalne zajednice u Vojvodini. Shodno tome osnovna delatnost društva je izdavanje, štampanje i distribucija dnevnog lista Magyar SZO, njegovih pratećih priloga $\mathrm{i}$ vršenje svih vrsta štamparskih usluga za treća lica prema zahtevima korisnika.

U društvu je, s obzirom na svoju delatnost, radni proces organizovan preko poslova vezanih za izdavanje dnevnog lista (novinari, urednici, fotoreporteri), administrativnih poslova (komercijalni, ekonomski i opšti poslovi) i poslova vezanih za izradu grafičkih proizvoda (poslovi vezani za proizvodnju u štampariji).

\section{INTEGRALNI SISTEM UPRAVLJANJA OTPADOM}

Integralni sistem zbrinjavanja otpada je zasnovan na analizama, razmatranju i definisanju metoda i postupaka tretmana čvrstog otpada, polazeći od mogućnosti za njihovo smanjivanje, biranjem optimalnih puteva tretmana čvrstog otpada, od mesta njegovog nastanka do konačnog, po životnu sredinu i zdravlje živih bića - neškodljivog zbrinjavanja. Koncepcija zbrinjavanja čvrstog otpada u integralnom sistemu obuhvata četiri osnovna principa:

1) izbegavati, koliko god je moguće,

2) koristiti, što je više moguće,

3) tehnički preraditi, koliko je potrebno i

4) deponovati, što je moguće manje.

Ovo je ujedno i hronološki red postupaka sa otpacima $u$ sistemu. Polazni princip predstavlja stalno smanjivanje količine tzv. neizbežnih otpadaka iz proizvodnje. Potom sledi korišćenje i prerada koje bi trebalo povećati i time smanjiti konačan ostatak za zbrinjavanje na deponijama. Analize su pokazale da efikasno iskorišćenje otpada može značajno smanjiti potrebe za primarnim sirovinama i energentima, uz istovremenu uštedu životnog prostora i zaštitu životne sredine.

\section{METODOLOGIJA}

U radu su korišćene dve metode prilikom analize:

- Dijagram uzroci-posledica (Ishikawa dijagram)

- Dijagram toka

„Dijagram UZROCI - POSLEDICA predstavlja metodu za detaljnu analizu odnosa između određenog stanja posmatranog sistema (posledice) i uticajnih veličina koje uslovljavaju pojavu datog stanja (uzroka)“ [5].

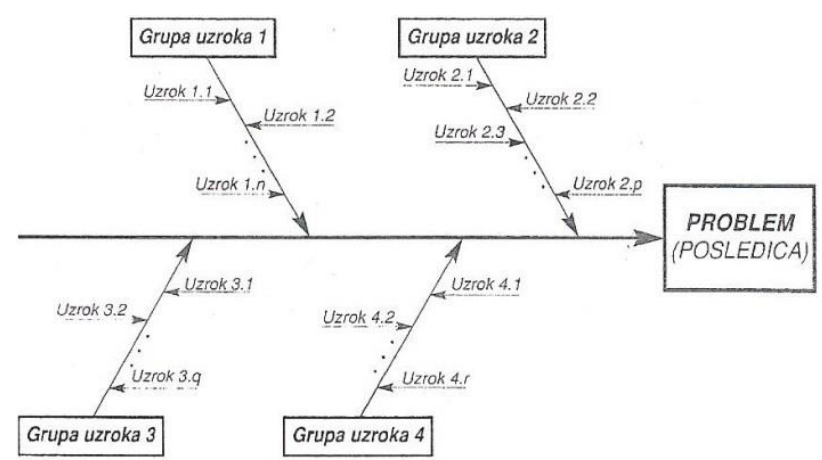

Slika 1: Ishikawa dijagram

„Dijagram toka predstavlja tehniku grafičkog prikazivanja načina odvijanja nekog procesa. Prilikom izrade dijagrama toka, koriste se sledeći simboli prikazani u tabeli““ [6].

Tabela 1: Simboli za crtanje dijagrama toka

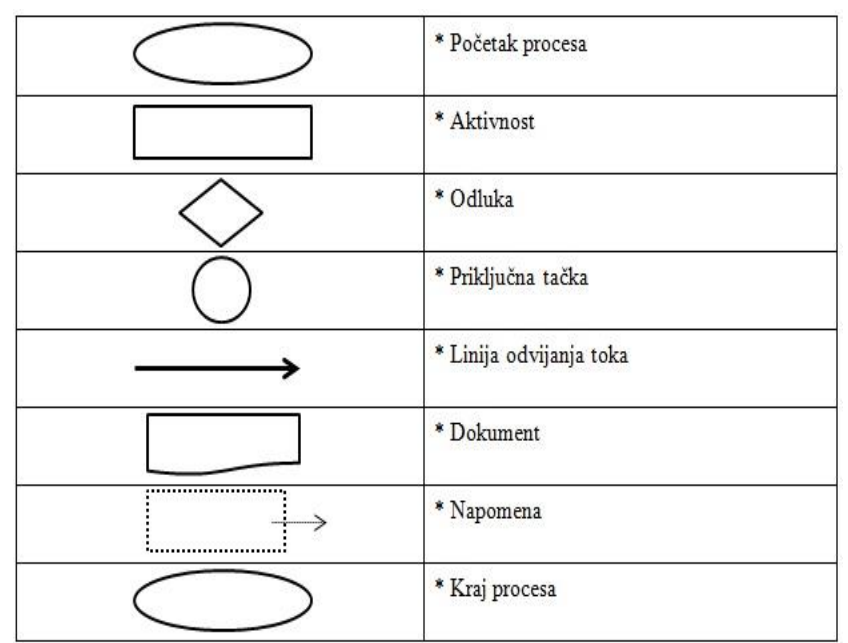

\section{SNIMAK STANJA SA IZDVAJANJEM PROBLEMA}

Proces skladištenja u preduzeću Magyar Szo ima funkciju očuvanja kvaliteta proizvoda/sirovina koje se skladište u magacin.

Analizom uticaja procesa skladištenja na životnu sredinu, izvršene putem internih dokumenata preduzeća, za elemente potrošnja resursa, komunalni otpad, neopasan otpad i opasan otpad, došlo se do sledećih zaključaka:

- potrošnja resursa (papir, boja, ofset ploče) ima srednji uticaj na životnu sredinu, te zahteva racionalno korišćenje istih; isto važi i za potrošnju vode i električne energije, dok toplotna energija ima mali uticaj na životnu sredinu

- komunalni otpad ima srednji uticaj na životnu sredinu; u okviru preduzeća vrši se sakupljanje otpada, koji se kasnije predaje preduzeću GREENTECH DOO sa kojim ima potpisan ugovor

- neopasan otpad ima značajni uticaj na životnu sredinu, te zahteva kontinualno sakupljanje, klasifikaciju, privremeno skladištenje i predaju na reciklažu ovlašćenim operaterima koji dalje manipulišu sa njim

- opasan otpad ima značajan uticaj na životnu sredinu, te je neophodno kontinualno sakupljanje, klasifikacija, privremeno skladištenje i predaja otpada na tretman ovlašćenom operateru. 
Kod samog procesa skladištenja, prvi korak u procesu skladištenja jeste prijem i odlaganje primljene robe, koje vrši magacioner - viljuškarista, na mesto koje je unapred predviđeno za to. Ova aktivnost vrši se primenom sredstava unutrašnjeg transporta. Ulazni dokument koji prati ovu aktivnost jeste prijemnica koja predstavlja dokaz o prijemu robe, dok se kao izlazni dokument javlja kartica artikla koja sadrži podatke o proizvodu koji se skladišti u magacin. Nakon prijema robe neophodno je obezbeđenje osnovnih elemanta za identifikaciju i sledljivost primljene robe. Nakon prijema robe u magacin, magacioner-viljuškarista unosi podatke o primljenoj robi u karton materijala. On treba da sadrži broj narudžbe, broj šarže i broj MSDS liste, ako je dostavljen pri isporuci. Ove podatke mora da sadrži i otpremnica i prijemnica dobavljača. Nakon što su obezbeđeni osnovni elementi za identifikaciju i sledljivost, informacije o kvalitetu robe se putem MSDS liste prosleđuju odeljenju nabavke.

Sledeća aktivnost je trebovanje materijala, koje šef odeljenja vrši po potrebi. Vrši se popunjavanjem blok obrasca, koji se dostavlja magacinu. U sledećoj aktivnosti magacioner-viljuškarista izdaje traženi materijal, uz potpisanu izdatnicu RN (u okviru IPOS-a) ili internu otpremnicu (kada se materijal ne vezuje za RN). Aktivnost koja se takođe pojavljuje prilikom procesa skladištenja jeste evidencija o periodičnim pregledima i intervencijama na vagi za merenje robe. Ova aktivnost se radi periodično pre isteka prethodnog pregleda ili po potrebi za servis, $u$ magacinu I i II pogona. Ovu aktivnost prate obrasci Q2.ŠT.05-01 Karton merila za I pogon i Q2.ŠT.05-02 Karton merila za II pogon. Nakon izdavanja materijala, vrši se prijem i označavanje materijala na odeljenju, u priručnom magacinu.

Ukoliko materijal nije u originalnoj ambalaži, neophodno je obezbediti odgovarajuću identifikacionu karticu/nalepnicu za određeni materijal. Kod ambalažiranja, skladištenja i rukovanja materijalom, neophodno je pridržavati se postupka - Q2.EM.07 Rukovanje opasnim materijama, i uputstva - Q3.EM.07-01 osnovni podaci o opasnim materijama u procesu proizvodnje. Nakon izdavanja materijala, vrši se ažuriranje stanja na magacinu, u magacinu repromaterijala, na kartonu uz odgovarajuću prijemnicu i izdatnicu. Informacija o novom, ažuriranom stanju, dostavlja se odeljenju nabavke i odeljenju knjigovodstva. Prilikom nastanka neopasnog/opasnog otpada, u pogonu na unapred predviđenom mestu, vrši se razvrstavanje, rukovanje, čuvanje kvaliteta, adekvatno skladištenje, a nakon upotrebe odlaganje/ptredaja otpada. Evidencija količine otpada po vrstama vrši se na listu o preuzimanju otpada/opasnog otpada na privremeno skladištenje. Šef proizvodnje, odnosno odgovorno lice za upravljanje otpadom vrši nedeljni nadzor nad sprovođenjem odredbi iz prethodne aktivonsti, tako što vrši detaljan pregled skladišnog i radnog prostora.

Kod aktivnosti provera stanja kvaliteta robe $\mathrm{u}$ magacinu/privremenom magacinu vrši se vizuelna provera: stanja ambalaže, količine, postojanja akcidentne sit., neovlašćenog pristupa, roka trajanja i čitkosti oznaka. Ova provera vrši se jednom mesečno. Kao poslednja aktivnost kod procesa skladištenja javlja se predaja nastalog otpada iz odeljenja u skladište opasnog/neopasnog otpada. Ova aktivnost vrši se periodično prema generisanoj količini (za svaku vrstu otpada vezuje se određena minimalna količina koju je neophodno prikupiti). Kao dokaz o preuzimanju otpada sa odeljenja javlja se list o preuzimanju otpada/opasnog otpada. Celokupna aktivnost vrši se u skladu sa postupkom Q2.EM.03 Upravljanje otpadom i opasnim materijama.

\section{ANALIZA PROBLEMA}

U skladišnim sistemima, distributivnim i logističkim centrima kriju se značajne rezerve, gubici i potencijalne mogućnosti za uštede. Procenjuje se da 20-25\% ušteda u lancu snabdevanja može da se ostvari na području skladišta. Da bi se navedeni potencijali iskoristili potrebno je primeniti i sprovesti različite mere i rešenja [7]. Jedno od rešenja jeste uvođenje elektonskog uređaja - skenera u proces skladištenja. Evidencija robe u skladištu vrši se poluautomatski, što znači da se roba fizički obeležava visećim ili ležećim karticama, a obrada stanja, naziva, broja se vrši automatski (pomoću računara). U preduzeću Magyar Szo poluautomatska evidencija podrazumeva korišćenje programskog modula IPOS u sklopu finansijsko-računovodstvenog odeljenja (knjigovodstva) i nabavnog odeljenja, kao i ručnu evidenciju na kartonu materijala koju vodi magacionerviljuškarista. Kako proces skladištenja nema negativan uticaj na životnu sredinu, fokus unapređenja stavljen je na samo poslovanje, tačnije na evidenciju robe u skladištu. Kako je gore napisano, trenutno se evidencija robe $u$ skladištu vrši poluautomatski. Unapređenje ovog procesa je moguće ukoliko se pređe na automatsku evidenciju robe $u$ skladištu. Kao nedostatak poluautomatske evidencije robe javljaju se greške prilikom popisa robe, otežan rad magacionera, otežano lociranje robe u skladištu...

\section{PREDLOG UNAPREĐENJA}

Unapređenje koje je uočeno prilikom analize procesa skladištenja jeste uvođenje elektronskog uređaja - skenera $u$ poslovanje. Uvođenje hardvera (bar-kod skenera) i njegova svakodnevna upotreba $\mathrm{u}$ procesu poslovanja skladišta dovodi do isključivanja ljudske greške, do kojih neminovno dolazi kada se podaci u sistem unose ručno - elektronski uređaj (skener) stara se o porudžbinama i otpremnicama i njihovoj preciznosti. Zaposleni u skladištu su opremljeni ručnim terminalima koji mogu da skeniraju bar-kodove i da im daju instrukcije gde da idu, na koju poziciju u skladištu i koji su sledeći artikli koje treba da komisioniraju. Uz prenos podataka u realnom vremenu, putem wi-fi mreže, ne treba se čuditi što kretanje robe kroz takvo skladište dostiže značajno viši nivo protočnosti [8].

U okviru ovog predloga unapređenja, urađena je tehnoekonomska analiza, koja predstavlja alat za određivanje opravdanosti investicije, dok će se ovde koristiti kako bi se utvrdilo vreme povrata ulaganja. Ulaganje koje je neophodno u uvođenje elektronskog uređaja - skenera jeste 105.000,00 dinara, s obzirom da preduzeće posluje na dve lokacije $\mathrm{i}$ da je u skladištu pogon II neophodno postojanje dva skenera, a u skladištu pogon I dovoljan je jedan skener. U obzir su uzete prosečne cene uređaja (35.000,00 po komadu). Planiran godišnji prihod za tekuću 2019. godinu jeste 399.637.000,00 dinara, dok je planirani godišnji rashod za tekuću godinu 389.900.000,00 dinara (prema finansijskom i poslovnom planu). Kada se izračuna čista dobit, dobija se iznos u 
visini od 737.000,00 dinara za tekuću godinu. S obzirom da iznos investicije nije velik, posmatraće se period povrata ulaganja u mesecima, jer se polazi od pretpostavke da će kumulativni neto novčani tokovi biti pozitivni u okviru jedne godine.

Tabela 2: Period povrata ulaganja

\begin{tabular}{|r|r|r|}
\hline MESEC & NETO NOVČANI TOK & $\begin{array}{r}\text { KUMULATIVNI NETO } \\
\text { NOVČANI TOK }\end{array}$ \\
\hline 6 & -105.000 & -105.000 \\
\hline 7 & 30.000 & -75.000 \\
\hline 8 & 10.000 & -65.000 \\
\hline 9 & 15.000 & -50.000 \\
\hline 10 & 20.000 & -20.000 \\
\hline 11 & 10.000 & -10.000 \\
\hline 12 & 10.000 & 0 \\
\hline
\end{tabular}

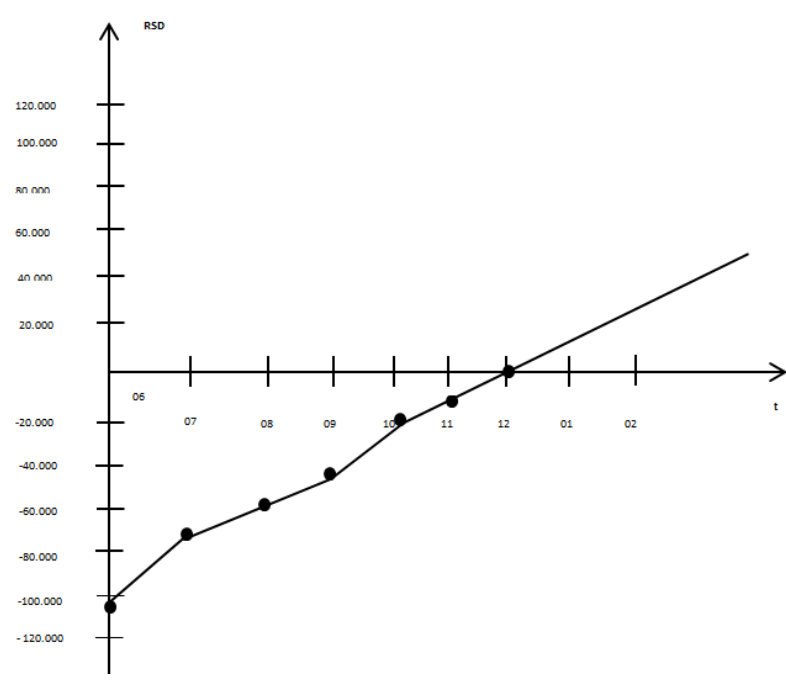

Slika 2: Grafički prikaz povrata ulaganja

Iz podataka koji su prikazani u tabeli 2 vidi se da je period povraćaja ulaganja 6 meseci. Naime, postepenim oduzimanjem mesečnih neto novčanih tokova od vrednosti inicijalnog kapitalnog ulaganja (šesti mesec) došlo se do toga da se vrednost mesečnih neto novčanih tokova izjednačila sa vrednošću inicijalnog kapitalnog ulaganja u 12. mesecu eksploatacije projekta. Kriva prikazuje podatke iz tabele - grafički prikaz perioda povraćaja ulaganja (slika 2).

\section{ZAKLJUČAK}

Izvršena je analiza aspekta životne sredine i kako proces skladištenja utiče na životnu sredinu i došlo se do zaključka da u preduzeću i samom poslovanju nema negativnih uticaja na životnu sredinu. Isto važi i za preostala dva procesa - proces nabavke i proces novinske rotacije, koji su na isti način analizirani i prikazani u samom radu.

Preduzeće Magyar Szo ima sistem upravljanja otpadom koji ne narušava životnu sredinu - ima uspostavljen sistem zbrinjavanja otpada koji je u skladu sa propisima.

$\mathrm{Na}$ osnovu celokupnog rada, analizom poslovanja preduzeća Magyar Szo može se zaključiti da ono dobro posluje i da bi primenom unapređenja koja su data moglo samo da podigne poslovanje na viši nivo.

\section{LITERATURA}

[1] https://www.iss.rs/rs/standard/?natstandard document_id=50783 (pristupljeno u aprilu 2019.)

[2] http://odgovornoposlovanje.rs/csr/zivotna-sredina (pristupljeno u maju 2019.)

[3] Božičković, Z., Upravljanje skladišnim sistemima, Doboj Saobraćajni fakultet 2012.

[4] Dr. Vojislav Vulanović, Sistem menadžmenta kvalitetom, Novi Sad, 2012.

[5] Dr. Dragutin Stanivuković, Metode i tehnike unapređenja procesa rada, Novi Sad, 2012. str: 122

[6] Vulanović i dr.; Metode i tehnike unapređenja procesa rada, Novi Sad, 2012.

[7] http://plutonlogistics.com/en/logistics/5-mart-2017smanjenje-troskova-u-logistici-kako-racionalizovatiskladiste/ (pristupljeno u maju 2019.)

[8] https://blog.spica.com/srpski/prijem-i-otprema-robeskladisni-promet/ (pristupljeno u maju 2019.)

\section{Kratka biografija:}

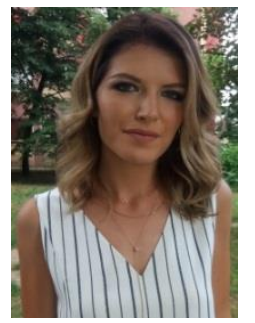

Ivona Varga rođena je u Novom Sadu 18.10.1993. god. Zvanje diplomirani inženjer menadžmenta stekla je 2016. godine. Master rad na Fakultetu tehničkih nauka iz oblasti Industrijsko inženjerstvo i menadžment odbranila je 2019. godine. 